\title{
Polycystic kidney disease: inheritance, pathophysiology, prognosis, and treatment
}

\author{
This article was published in the following Dove Press journal: \\ International Journal of Nephrology and Renovascular Disease \\ 22 June 2010 \\ Number of times this article has been viewed
}

\author{
Christian R Halvorson' \\ Matthew S Bremmer' \\ Stephen C Jacobs' \\ 'Department of Surgery, University \\ of Maryland School of Medicine, \\ Baltimore, MD, USA
}

\begin{abstract}
Both autosomal dominant and recessive polycystic kidney disease are conditions with severe associated morbidity and mortality. Recent advances in the understanding of the genetic and molecular pathogenesis of both ADPKD and ARPKD have resulted in new, targeted therapies designed to disrupt cell signaling pathways responsible for the abnormal cell proliferation, dedifferentiation, apoptosis, and fluid secretion characteristic of the disease. Herein we review the current understanding of the pathophysiology of these conditions, as well as the current treatments derived from our understanding of the mechanisms of these diseases.
\end{abstract}

Keywords: Polycystic kidney disease, autosomal dominant, recessive, end stage renal disease

\section{Introduction}

Polycystic kidney disease (PKD) is an inherited disorder characterized by cystic expansion of the kidneys producing progressive kidney enlargement and renal insufficiency, in addition to various extrarenal manifestations. The disease can be inherited in autosomal dominant and recessive forms. Autosomal dominant polycystic kidney disease (ADPKD) is characterized by slow but progressive enlargement of the kidneys with renal failure occurring by the fifth to sixth decade of life. ${ }^{1}$ The disease occurs in approximately 1:800 to 1:1,000 people and accounts for $2.5 \%$ of all cases of end-stage renal disease. ${ }^{1,2}$ Clinically, ADPKD presents over the course of decades with hypertension, flank pain, hematuria, and renal cyst infections in adults. Cyst development and growth is gradual, yet despite the massive growth of the kidneys (Figure 1), the glomerular filtration rate (GFR) in these patients is typically conserved until ages $30-40$, followed by a rapid, linear decline after this time. ${ }^{2,3}$ By the age of $70,50 \%$ of patients with ADPKD will require dialysis or kidney transplantation. ${ }^{4}$

Autosomal recessive polycystic kidney disease (ARPKD), by contrast, typically presents in a younger patient population. ${ }^{5}$ The disease is characterized by cystic dilation of the collecting ducts of the kidneys, along with dysgenesis of the biliary ductal plate, resulting in congenital hepatic fibrosis and often death in the perinatal period due to respiratory failure. ${ }^{6,7}$ The disease has an estimated incidence of 1 out of 20,000 live births and presents with four distinct phenotypes as proposed by Blyth and Ockenden, differentiation based on the age of presentation, the amount of biliary fibrosis, and the proportion of dilated renal collecting ducts..$^{7-9}$ Despite varying clinical presentations, all phenotypes have been linked to a single gene, $P K H D 1 .{ }^{10}$
Correspondence: Christian Halvorson 405 W. Redwood St., Baltimore, MD 21201

Email chalv00I@umaryland.edu 


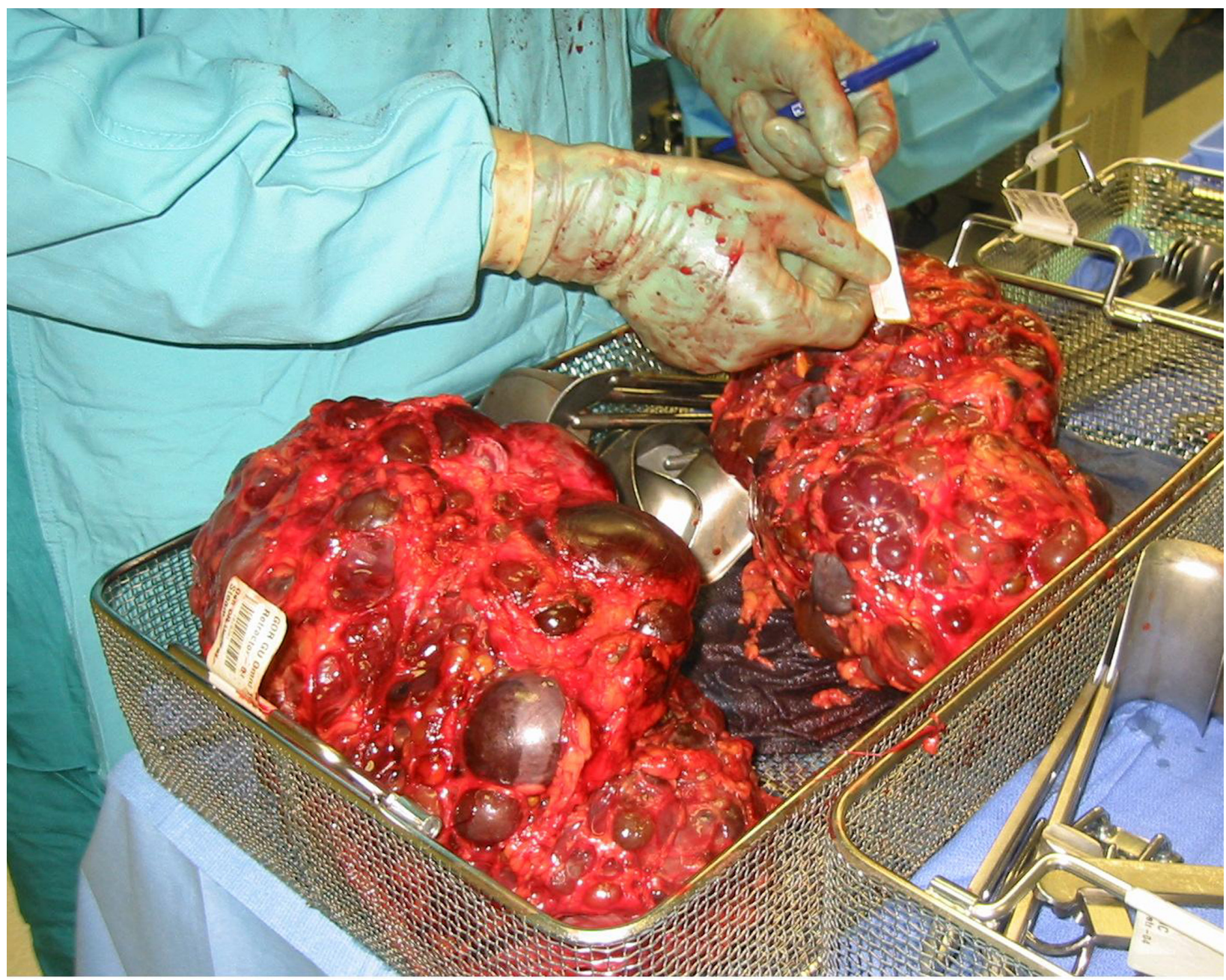

Figure I Explanted polycystic kidneys reveal the massive expansion resulting from progressive cystic growth.

\section{Clinical presentation ADPKD}

The majority of patients with ADPKD have few or no symptoms at the time of diagnosis. When symptoms do occur, they typically begin between 30 to 50 years of age, and most commonly include acute abdominal or flank pain. ${ }^{11,12}$ The most common clinical manifestation of ADPKD is hypertension, which has been found to be present in as many as $60 \%$ of patients before the impairment of renal function, and nearly all patients by the time they progress to ESRD. ${ }^{13-15}$ Other presenting signs and symptoms include palpable kidneys, microscopic or gross hematuria, recurrent urinary tract infections, lower back discomfort, shortness of breath, and early satiety. ${ }^{16}$

The most common extrarenal manifestation of ADPKD is the development of hepatic cysts, which usually occur after the development of renal cysts, and are incidental findings in most patients. ${ }^{17}$ Other findings in ADPKD include pancreatic, thyroid, subarachnoid, and seminal vesicle cysts. ${ }^{1}$ The most lethal extrarenal manifestations of ADPKD are intracranial aneurysms, which has been found to be present in up to $40 \%$ of ADPKD patients. ${ }^{18}$ These aneurysms can rupture, causing intracranial hemorrhage and death in $8 \%$ to $11 \%$ of patients. Additional vascular findings in ADPKD include cardiac valvular disease, and less commonly, thoracic, iliac, and abdominal aortic aneurysms, coronary artery aneurysms, intracranial arterial dissection, intracranial arterial dolichoectasia, and megadolichobasilar artery. ${ }^{19-23}$

Nephrolithiasis is another common complication of ADPKD, occurring in $20 \%-30 \%$ of patients. ${ }^{24}$ Stone formation should be suspected in any ADPKD patient with an acute onset of pain, hematuria, or deteriorating kidney function. Stone composition is typically uric acid or calcium oxalate, with decreased ammonia excretion, low urinary $\mathrm{pH}$, low citrate concentration, and urinary stasis thought to contribute to stone formation. ${ }^{12}$ The presence of stones can 
be confirmed with either renal ultrasonography (US) or CT scanning, with the latter being better at detecting stones given the limitations of US in the presence of parenchymal or cyst wall calcifications. ${ }^{25}$

\section{ARPKD}

ARPKD has a variable clinical presentation and age of onset, with most cases being diagnosed in utero or shortly after birth. In the most severe cases, ARPKD can be detected in utero by the presence of very large echogenic kidneys that occupy much of the abdominal cavity, along with oligohydramnios, due to inadequate renal development. ${ }^{5,26}$ These patients typically display the characteristic 'Potter' phenotype, with findings that include pulmonary hypoplasia, extremity abnormalities, unusual facial appearances, and deformities of the spine, all of which can be attributed to lack of amniotic fluid. ${ }^{5}$ These patients often die in the neonatal period due to respiratory complications rather than renal failure, with their renal insufficiency rarely severe enough to be fatal. ${ }^{5}$ Liver disease in this age group is typically insignificant, although microscopic disease can be seen..$^{27,28}$ Delayed presentations are also possible with ARPKD, with some patients having no clinical or laboratory abnormalities until later in childhood. ${ }^{27}$ Presenting signs and symptoms in these patients are often due to complications of congenital hepatic fibrosis, which include portal hypertension, cholangitis, and hepatomegaly. Abnormal laboratory findings can also lead to the diagnosis in these patients, and may include asymptomatic elevated creatinine, hematuria, proteinuria, and hypertension.

Other manifestations of ARPKD include electrolyte abnormalities, most commonly hyponatremia, and urinary tract infections from enteric organisms, including Escherichia coli, Enterobacter, and Klebsiella. ${ }^{7}$ Extrarenal cysts are less commonly seen in ARPKD compared to autosomal dominant disease, but have been reported in the liver and pancreas..$^{29}$ Intracranial aneurysms have also been described, although this finding is extremely rare, possibly due to the low average life-expectancy in this group of patients. ${ }^{30,31}$

\section{Evaluation and diagnosis ADPKD}

When ADPKD is suspected, patients should be evaluated for a family history of disease, with specific questioning spanning three generations. Although no consensus criteria have been established, with a negative family history of disease, a presumptive diagnosis can be made when there are bilateral renal cysts, and when two of the following criteria are met: bilateral renal enlargement, more than two hepatic cysts, presence of a cerebral aneurysm, or if there is a solitary cyst in the arachnoid, pineal gland, pancreas, or spleen. ${ }^{32}$ Given that the number of renal cysts increases with age, it has been proposed that three or more cysts, either unilaterally or bilaterally, is sufficient to make the diagnosis in patients between 15 to 39 years of age. ${ }^{33}$ Likewise, patients between the ages of 40 and 59 require at least two cysts in each kidney, with at least four cysts required in each kidney to make the diagnosis in patients aged 60 and above. Although magnetic resonance imaging and computed tomography are likely more sensitive for cyst detection, ultrasound (US) is currently the imaging modality of choice in these patients. ${ }^{11,33}$ A genebased diagnosis of ADPKD is also possible, allowing for the detection of specific $P K D 1$ or $P K D 2$ mutations. This testing is not commonly performed, however, given the expense of the test and its ability to detect definitive mutations in only $41 \%-63 \%$ of cases. ${ }^{34,35}$

\section{ARPKD}

Autosomal recessive PKD can typically be diagnosed based on clinical findings alone, with liver and kidney biopsies needed only in rare instances (Table 1). ${ }^{36-38}$ In utero, the diagnosis is suggested by the presence of oligohydramnios, kidney enlargement, and the absence of urine in the fetal bladder, findings typically detectable by US at $18-20$ weeks gestation. DNA analysis by amniocentesis or chorionic villus sampling is currently not part of the routine evaluation of ARPKD patients, with its use typically limited to uncertain cases or for prenatal confirmation. ${ }^{39}$

\section{Inheritance ADPKD}

ADPKD results from mutations in the genes $P K D 1$ or $P K D 2$, which encode the proteins polycystin-1 and polycystin-2, respectively, with $P K D 1$ being located on the short arm of chromosome 16 (16p13.3 region) and $P K D 2$ on the long arm of chromosome 4 (4q21.2 region). ${ }^{1,40}$ Approximately eighty-five percent of cases of ADPKD have been found to

Table I Diagnostic criteria for ARPKD. Modified from Zerres et $\mathrm{al}^{37}$

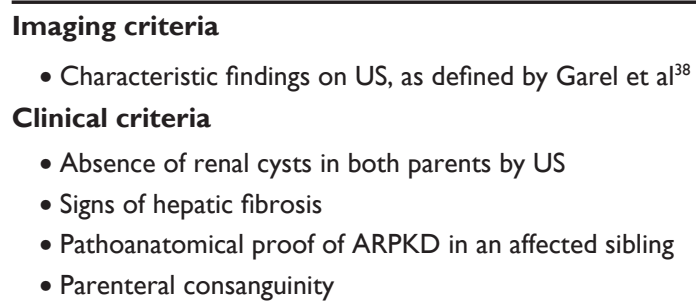

Notes: 'To meet diagnostic criteria, patients must meet imaging criteria and at least one of the clinical criteria 
be associated with mutations in $P K D 1$, with the other $15 \%$ due to PKD2 mutations. ${ }^{1,4}$ Mutations in PKD1 and PKD2 produce phenotypically similar presentations, however, as a group, patients with $P K D 1$ mutations generally have a larger number of renal cysts and progress more rapidly to end-stage renal disease. ${ }^{11,41,42}$ As the name suggests, ADPKD is inherited in an autosomal dominant fashion and has nearly complete penetrance. The disease is characterized by a 'second hit' phenomenon, in which a mutated dominant allele is inherited from a parent, with cyst formation occurring only after the normal, wild-type gene sustains a second genetic 'hit', resulting in renal tubular cyst formation and disease progression. ${ }^{11}$ Some data suggests that those individuals with milder disease courses may have incompletely penetrant PKD1 alleles, indicating that the level of functional PKD1 protein may be important for cyst initiation. ${ }^{43}$ There is also some suggestion that patients that inherit ADPKD from their father experience less severe disease, compared to maternally-inherited disease. ${ }^{44}$ Patients with heterozygous mutations of both $P K D 1$ and $P K D 2$ experience worse outcomes and more severe disease than those with either mutation alone, and homozygosity of PKD1 mutations is thought to be lethal in utero. ${ }^{45,46}$ Notably, there is a large amount of intrafamilial variability in ADPKD, with the difference in the age of ESRD found to be significantly higher in siblings $(6.9 \pm 6.0$ years) compared to monozygotic (MZ) twins $(2.1 \pm 1.9$ years $)$, suggesting a role for modifier genes that might contribute to this variability. ${ }^{47}$

Some families with ADPKD display neither PKD1 nor PKD2 mutations, suggesting that other genetic loci may also be associated with the disease. ${ }^{48-52}$ In general, these patients have milder disease, although a number of families with more severe clinical courses have been described. ${ }^{52,53}$ Reasons for this phenotype heterogenicity are unclear, and it is possible that more than one unknown gene is causative in these unlinked families. ${ }^{53}$

\section{ARPKD}

ARPKD is a disease primarily of infants and children and is caused by mutations at a single locus, the Polycystic Kidney and Hepatic Disease 1 gene (PKHD1), located on chromosome $6 \mathrm{p} 12 .{ }^{10} \mathrm{PKHD} 1$ encodes the protein fibrocystin which, similar to polycystin-1 and polycystin-2, has been found to localize in the primary cilium and basal body of the renal and bile duct epithelium. ${ }^{54}$ There are currently over 300 recognized mutations in $P K H D 1$, with the most severe cases often the result of truncating mutations, often resulting in perinatal or neonatal death. ${ }^{55-60}$ Only about $10 \%-20 \%$ of cases of ARPKD are associated with commonly occurring PKHD1 mutations, with the majority of mutations being rare variants and as many as one third of all mutations seen exclusive in single families. ${ }^{61,62}$ Correlations between ARPKD genotypes and phenotypes are limited, but studies have found genotypes consisting of two truncating mutations to be lethal, and those with at least one missense mutation to be compatible with life, likely through production of a partially-functional protein product. ${ }^{63}$

\section{Pathophysiology}

Recent evidence suggests that the primary abnormality leading to cyst formation in both the autosomal dominant and recessive forms of PKD is related to defects in cilia-mediated signaling activity. ${ }^{40}$ Specifically, PKD is thought to result from defects in the primary cilium, an immotile, hair-like cellular organelle present on the surface of most cells in the body, anchored in the cell body by the basal body. ${ }^{40,64}$ In the kidney, primary cilia have been found to be present on most cells of the nephron, projecting from the apical surface of the renal epithelium into the tubule lumen. ${ }^{64}$ In response to fluid flow over the renal epithelium, the primary cilium is bent, resulting in a flow-induced increase in intracellular calcium. ${ }^{65}$

In a 2009 review of the pathogenesis of PKD, Patel et al discuss the accumulating evidence supporting the role of the primary cilium in PKD. ${ }^{40}$ They note the identification of polycystin-1, polycystin-2, and fibrocystin, the proteins associated with ADPKD and ARPKD, within the primary cilia and basal body of renal tubular epithelia, suggesting that defects in these proteins and subsequent cilia formation may lead to PKD. ${ }^{66}$ The same has been found to be true for other cyst-producing conditions, including nephronophthisis and Bardet-Biedl syndrome, where causative proteins have also been localized to the primary cilia and basal body. Additional evidence for the role of the primary cilium in PKD comes from the finding that transgenic mice with kidney-specific knockouts of Kif3a, a motor protein subunit required for cilia formation, produce renal cysts in mice similar to those seen in human PKD. ${ }^{67}$ While it is not known how defects in the primary cilium lead to cyst development, it is thought to possibly be related to disruption of one of the many signaling pathways regulated by the primary cilium, including intracellular calcium, Hedgehog, Wnt/ $\beta$-catenin, cyclic adenosine monophosphate (cAMP), or planar cell polarity (PCP). ${ }^{40,68,69}$

PCP refers to the coordinated orientation of cells making up most of the organs of the body in a plane vertical to the 
apical/basal axis of the cell sheet. ${ }^{70} \mathrm{PCP}$ is thought to play an essential role in the organogenesis of numerous organ systems through direction of cell migration, polarized cell division, and cellular differentiation, with disruption of this organization thought to play an important role in the etiology of PKD. ${ }^{40}$ The role of PCP in the etiology of PKD was originally demonstrated by Fischer et al who found that PCK rats (carrying mutations in PKHD1), had randomized patterns of cell division, contributing to tubular dilation and cyst formation. ${ }^{69}$ This was in comparison to wild-type renal tubules, which were found to divide along an axis roughly parallel to the longitudinal axis of the tubule. This polarity is thought to be regulated by the primary cilium, as mice with the inactivated Kif3a gene have also been found to display disorganized cell division, suggesting disrupted PCP. ${ }^{71}$ Similar findings have been found with inactivation of other genes required for ciliogenesis, strengthening the role of the primary cilium in the regulation of $\mathrm{PCP} .{ }^{72}$ Recent evidence suggests that disrupted PCP may play a role solely in the pathogenesis of ARPKD, as mouse models of PKDI and $P K D 2$ mutations have been found to lose cell-oriented division only after cyst formation has begun, unlike models of PKHD1.73

Accordingly, with mutations in PKD1, PKD2, or PKHD1, function of the primary cilium is impaired, resulting in disruption of a number of intracellular signaling cascades that produce dedifferentiation of cystic epithelium, increased cell division, increased apoptosis, and loss of resorptive capacity. ${ }^{74,75}$ These signaling pathways have been found to include cAMP-activated, Wnt signaling, and mammalian target of rapamycin (mTOR) pathways, the discoveries of which have greatly expanded the number of potential therapeutic targets for the disease. ${ }^{76}$ Ultimately, cyst growth and expansion compresses renal vessels and leads to intrarenal ischemia and activation of the renin-angiotensin-aldosterone system (RAAS), in turn producing progressive cyst expansion, increased systemic vascular resistance, sodium retention, and renal fibrosis. ${ }^{77}$

Vascular manifestations of ADPKD are thought to also be related to abnormal functioning of polycystin-1 and polycystin-2, which additionally have been found to be expressed in vascular smooth muscle and endothelium..$^{78,79}$ Polycystin-1 and polycystin-2 associate with one another and form a 'receptor-ion channel complex' on the membrane of primary cilia of renal epithelial cells as well as endothelial cells. Here, luminal sheer stress is thought to be sensed by polycystin-1, opening the calcium-permeable channel polycystin-2 which leads to a series of calcium-dependent signaling cascades. ${ }^{80-82}$ When this mechanosensory function is lost in ADPKD, calcium signaling is disrupted, contributing to cyst formation and numerous vascular alterations. ${ }^{83}$ More recently, studies have suggested a role for polycystins in pressure-sensing within arterial myocytes, showing that the ratio of polycystin-1 to polycystin-2 regulates the opening of stretch-activated cation channels, modulating the arterial response to changes in intraluminal pressure. ${ }^{84}$ Additional work has revealed that a reduced dose of $P K D 1$ in mouse models is associated with vascular dysfunction, resulting in age-dependent increases in vascular reactivity. ${ }^{85}$ This reactivity is thought to be the result of altered intracellular calcium homeostasis and compensatory changes in transport proteins involved in calcium signaling, producing alteration of endothelium-dependent relaxation and increased systolic blood pressures. Accordingly, PKD1 haploinsufficiency, and dosages of polycystin- 1 and -2 , are thought to play an important role in vascular smooth muscle intracellular calcium homeostasis, and thus in the pathogenesis of vascular changes seen in ADPKD.

\section{Prognosis ADPKD}

Children with ADPKD are usually asymptomatic. Nonetheless, it is estimated that as many as $1 \%-2 \%$ of patients may present with early-onset disease, defined as symptoms occurring prior to age $15 .{ }^{86} \mathrm{In}$ fact, in the most severe cases, ADPKD may present with significant neonatal and perinatal morbidity and mortality, a clinical course more characteristic of ARPKD ${ }^{87}$ More commonly, symptoms of disease begin between the ages of 30 to 50 , and include acute abdominal or flank pain and gross or microscopic hematuria. ${ }^{11}$

Despite the slow and steady cystic growth in ADPKD patients, renal function is maintained for years and even decades, typically remaining stable until a critical kidney size is reached, after which the decline in GFR is rapid. ${ }^{3}$ Support for this theory comes from a study of 284 patients with ADPKD which found the onset of ESRD to occur in all patients within 5 years of the kidneys being palpated on physical examination. ${ }^{88}$

Much of our data on the natural history of ADPKD comes from a cohort of patients representing the Consortium for Radiologic Imaging Studies in Polycystic Kidney Disease (CRISP), a group of 241 ADPKD patients between the ages of 15 to 45 , all of whom had creatinine clearances greater than $70 \mathrm{~mL} / \mathrm{min}$ (Table 2). ${ }^{89}$ Using standardized MRI renal imaging, these patients were evaluated annually for 3 years in order to determine reliable measures of disease 
Table 2 Select findings from the CRISP cohort

- The rate of cyst growth is continuous but heterogeneous, varying from individual to individual

- The mean renal growth rate was found to be $5.3 \%$ per year, or about $63.4 \mathrm{~mL}$ per year

- Larger kidneys have a faster rate of growth and are associated with a more rapid disease course

- PKDI genotypes are associated with larger kidneys compared to PKD2 patients, with no significant difference in cyst growth rate

- Normotensive patients have smaller cyst and renal volumes compared to hypertensive counterparts

- Cystic liver disease was present in $83 \%$ of participants, increasing in incidence with patient age

progression early in ADPKD. ${ }^{1}$ As a result, in a series of separate investigations, the CRISP cohort confirmed the notion that cystic growth and renal enlargement is significant prior to impairment of renal function..$^{89,90}$ The cohort also revealed that normotensive patients have smaller cyst and renal volumes compared to hypertensive counterparts. Cystic liver disease was found to be prevalent in ADPKD, with $83 \%$ of the CRISP cohort having liver cysts, women being more affected than men and with a great total cyst volume. In patients over the age of 35 years, 94\% displayed liver cysts, while only $55 \%$ of patients younger than 25 years of age had them. ${ }^{91}$ Polycystic liver disease can also occur as a genetically-independent entity, characterized by numerous liver cysts, but without renal involvement. Like ADPKD, the disease is inherited in an autosomal dominant fashion, with the majority of cases linked to mutations in two separate genes, PRKCSH and SEC63. ${ }^{12}$ These genes encode the glucosidase II $\beta$ subunit and the protein SEC63 and are involved in glycoprotein processing within the endoplasmic reticulum, with the molecular mechanism of cyst formation remaining unclear. ${ }^{12,92}$

CRISP participants were found to have a mean renal growth rate of $5.3 \% \pm 3.9 \%$ per year, or about $63.4 \mathrm{~mL} /$ year, with cyst growth and renal enlargement found to be a continuous and steady process in most patients. ${ }^{90}$ This was shown by Grantham et al who studied the ADPKD cohort with serial measurements of total kidney and cyst volumes over the 3 -year study. The investigators found that, in addition to their continuous and static growth rates, the increase in cyst volume appeared to be largely individualized, varying from patient to patient. Moreover, in most patients the kidneys grew at a similar rate bilaterally, leading the authors to conclude that cysts within ADPKD patients were likely programmed to grow at uniform rates that can vary from patient to patient. This finding has practical prognostic implications, specifically, that
ADPKD patients with larger kidneys at any given age will likely experience more complicated and rapid clinical courses compared to similarly-aged patients with smaller kidneys. Evidence for this assumption comes from the study, which found that patients younger than 30 with large kidneys, greater than $1500 \mathrm{~mL}$, demonstrated the greatest kidney growth rate of all ADPKD patients (12.7\% per year). ${ }^{90}$

An important prognostic factor in ADPKD is the genotype of the patient, with $P K D 1$ mutations having being found to result in earlier onset hypertension and younger end-stage renal disease compared to patients with $P K D 2$ mutations. ${ }^{93-96}$ This again was shown in the CRISP cohort, where patients with PKD2 mutations were found to have significantly smaller renal volumes and fewer cysts..$^{41,89}$ Notably, the rate of cyst growth was not found to be significantly different between $P K D 1$ and $P K D 2$ patients. Additional studies have found the mean age to ESRD to be 53 in patients with $P K D 1$ mutations, compared to 69 in patients with $P K D 2 .{ }^{94}$ Additional factors found to have negative prognostic implications in ADPKD include a younger age at diagnosis, male gender, hypertension, increased left ventricular mass, hepatic cysts in women, three or more pregnancies, gross hematuria, urinary tract infections in men, and increased renal volume. ${ }^{96}$

Given the success of renal replacement therapy in ADPKD, cardiovascular complications have emerged as a major cause of morbidity and mortality in this group..$^{97,98}$ Hypertension has been found to be nearly universally present in ADPKD patients with ESRD, with left ventricular hypertrophy seen in over $70 \%$ of these patients when beginning dialysis. ${ }^{15,99}$ This finding is a risk factor for premature cardiovascular death, and is an important cause of morbidity and mortality in ADPKD patients. ${ }^{100}$ Moreover, given the association between ADPKD and intracranial aneurysms, patients with family members with ruptured intracranial aneurysms should be screened for evidence of disease, as familial clustering of cases has been noted. ${ }^{101}$

\section{ARPKD}

The natural history of autosomal recessive polycystic kidney disease is variable, but has been well described in a number of retrospective studies following these patients over time. These reports have found the 1-year death rate for ARPKD varying widely from $9 \%-81 \%$, with the majority of studies falling between $9 \%-13 \% .{ }^{7,28,37,102-104}$ The most common causes of death include respiratory failure or sepsis. In a recently described cohort of 31 patients with ARPKD followed between 1990 and 2000, 55\% of patients were found to present in the neonatal period, with the most common 
clinical signs being respiratory distress or palpable kidneys on physical examination. ${ }^{7}$ Pulmonary complications are extremely common in the newborn period, and have been found to occur in anywhere from $13 \%-75 \%$ of ARPKD patients, with ventilatory support being temporarily required in $40 \%$ of cases. ${ }^{7,86,102,105}$ The requirement of neonatal ventilatory support has been thought to be a negative prognostic factor, as it often implies more severe pulmonary hypoplasia and is associated with greater renal complications. ${ }^{7,106}$ Patients diagnosed as neonates who do not experience significant respiratory complications may have a better prognosis, with studies finding that renal clearances often improve in the first two years of life in these patients, later stabilizing before declining in adolescence. ${ }^{7,102}$ Some suggest that another important prognostic factor in ARPKD is the age of disease onset, with a number of studies having shown that the later the age of diagnosis, the better the long term survival. ${ }^{102,103,107,108}$ The data for this is conflicting, however. ${ }^{7,103,105}$ Overall, survival of ARPKD patients at 9 years of age has been found to be as high as $80 \%{ }^{7}$

Patients with ARPKD frequently experience congenital hepatic fibrosis, which has been found to be present in $11 \%-47 \%$ of patients, with patients that have delayed presentations often having more significant liver disease. ${ }^{7,27,28,37,102-104}$ The most common complication of hepatic fibrosis is portal hypertension, seen in $20 \%$ to $60 \%$ of patients, resulting in esophageal varices and bleeding in as many as $20 \%-36 \%$ of cases. ${ }^{37,102,107}$ Nonetheless, portal hypertension rarely affects hepatic function, and its complications are uncommonly fatal in ARPKD. ${ }^{107}$ Systemic hypertension is also seen in these patients, frequently most severe in infancy. As these patients age, hypertension has been shown to gradually decrease in severity, with some individuals even returning to normotensive states. ${ }^{7,37,103,107,109}$

\section{Treatment \\ Prevention of progression ADPKD}

Hypertension is a common and early manifestation of disease in ADPKD and, when uncontrolled, is associated with an earlier progression to end-stage renal disease and cardiovascular complications, compared to normotensive ADPKD patients. ${ }^{14,89,96,97}$ While it is recognized that hypertension affects renal and patient outcomes in ADPKD, the most beneficial antihypertensive medication in this patient population remains unclear, with agents that block the renin-angiotensinaldosterone system (RAAS) historically thought to be the most effective at treating ADPKD-associated hypertension.
Previous studies analyzing the benefit of RAAS blockade utilizing angiotensin-converting enzyme (ACE) inhibitors have revealed that hypertensive patients with ADPKD treated with diuretics have a faster rate of decline in GFR compared to patients treated with ACE inhibitors, despite similar blood pressure control. ${ }^{110}$ However, in a head-to-head comparison, enalapril has been shown to have no advantage over the calcium-channel blocker amlodipine in slowing GFR decline. ${ }^{111}$ Similarly, enalapril has been found to be no more effective than atenolol in slowing the decline in renal function, also showing no renoprotective effect when used preemptively in normotensive ADPKD patients. ${ }^{112}$

However, weaknesses of the aforementioned studies include that older patients were primarily studied, that there was limited follow-up, and that non-standardized medication dosing was used. Moreover, various different end-points were used in each study, and they primarily relied on outcomes measures, including GFR, which are ineffective measures of treatment efficacy early in the disease course due to the long presymptomatic phase of disease and delayed onset of renal insufficiency. ${ }^{1,2}$

While the data surrounding RAAS inhibition in ADPKD is still controversial, there remains evidence of increased circulating levels of plasma renin and aldosterone in ADPKD individuals, suggesting a continued role for RAAS inhibiting medications. ${ }^{113}$ Likewise, short-term therapy with ACE inhibitors has been shown to improve renal blood flow and proteinuria in ADPKD patients, with additional studies showing significant improvements in proteinuria and creatinine doubling with use of combination ACEI/ARB therapy in other proteinuric renal diseases. ${ }^{1,11,114,115}$ Accordingly, using novel MRI techniques developed in CRISP to evaluate changes in renal volume over short periods of time, the Halt Progression of Polycystic Kidney Disease (HALT PKD) network was developed to assess whether tight blood pressure control and rigorous blockade of RAAS could slow the progression of renal disease, as well as prevent cardiovascular complications of ADPKD. ${ }^{1}$ In particular, this study tests the efficacy of ACE inhibitors in combination with angiotensin receptor blockers. The logic for this approach comes from the incomplete blockade of RAAS seen with ACE inhibitor use alone, given the possibility of ACEindependent routes of angiotensin II generation, including the chymase pathway. ${ }^{116}$

Accordingly, the study recruited 1020 patients with the effects of combination therapy of ACE inhibitors and ARBs being tested in early disease (study A) and in cases of more advanced renal disease (study B). Study A consists 
of 548 patients, all of which have a GFR greater than $60 \mathrm{~mL} / \mathrm{min}$, randomized to receive either lisinopril plus placebo, or lisinopril plus telmisartan. The patients were further randomized to treatment groups consisting of standard blood pressure control (120-130/70-80 mmHg) versus rigorous BP control (95-110/65-75 $\mathrm{mmHg})$. Study B consists of 472 patients with GFRs ranging from 25 to $60 \mathrm{~mL} / \mathrm{min}$, again randomized to receive either lisinopril plus placebo or lisinopril plus telmisartan. The authors hypothesize that intense blockade of RAAS using the combination of ACE inhibitors and ARBs will delay the onset and progression of renal disease in ADPKD patients, with rigorous blood pressure control being most effective in limiting the progression of renal disease early on in ADPKD. At the completion of the study, the investigators hope to obtain better evidence for treatment of ADPKD-associated hypertension in early and late stages of disease. ${ }^{1,2}$

Other RAAS inhibiting agents that may hold promise in the future include the direct renin inhibitors, which have been shown to reduce blood pressure in a dose-dependent manner, reduce plasma renin activity, and decrease proteinuria while delaying renal failure in patients with diabetic and nondiabetic nephropathy. ${ }^{117}$ Long-term studies of the effects of this treatment class, in addition to comparisons with other RAAS inhibiting agents, are required before a conclusion can be made about its utility in renovascular conditions such as ADPKD.

Regardless of the agent utilized, tight blood pressure control has been shown to delay the progression of disease in ADPKD. Other currently-accepted treatment strategies in ADPKD include salt-restriction (no more than 6 grams of sodium chloride daily), low protein intake (no more than 1 gram per kilogram of body weight per day), regular exercise, maintenance of a healthy body weight, and frequent water intake. ${ }^{118}$

\section{Dialysis}

Dialysis is a common means of renal replacement therapy for patients with PKD awaiting kidney transplants. Options for PKD patients include both hemodialysis and peritoneal dialysis, though the latter is commonly thought to lead to poor outcomes due to concerns of abdominal wall complications, including leaks and intestinal perforation, in part due to increased intraabdominal pressure resulting from large kidney volumes. ${ }^{119-121}$ However, in a retrospective study of 56 patients with PKD receiving peritoneal dialysis, Kumar et al found no difference in patient survival, technique survival, and peritonitis rates after a mean of 37 months follow-up in PKD patients compared to nondiabetic ESRD controls. ${ }^{122}$ Increased intraabdominal pressure can make peritoneal dialysis more difficult, however, preventing the use of larger dwell volumes. Hemodialysis has also been shown to be an effective and safe means of renal replacement in ADPKD patients, with a 5-year survival 10\%-15\% higher than non-ADPKD controls, most likely related to decreased cardiac mortality in this group of patients. ${ }^{123}$

\section{Transplant}

ADPKD is a common cause of ESRD, requiring renal transplantation. In a 2009 study of 445 renal transplant patients, 48 of whom had ADPKD, the average age at transplant for ADPKD patients was found to be $51.2 \pm 8.6$, with there being no significant differences between ADPKD and other renal transplant patients in terms of the prevalence of post-transplant hypertension, proteinuria, erythrocytosis, acute rejection episodes, immediate graft function, and most importantly, graft and patient survival after 1 , 5, and 8 years. ${ }^{124}$ ADPKD patients did, however, have a significantly-increased incidence of developing diabetes mellitus post-transplant compared to non-ADPKD patients (33.3\% vs $17.1 \%)$. Simultaneous nephrectomy at the time of transplant can also be performed and has been shown in a recent study of 20 patients undergoing the procedure to produce minimal morbidity while avoiding the risks of interval dialysis, additional operations, hospitalizations, and anesthetic exposure. ${ }^{125}$ This combined approach is not without its potential complications, however, found in the study to include one instance of wound dehiscence, adrenal insufficiency, and liver laceration. Although the best patient population for this approach has not been defined, it has been suggested that the risks of this procedure are best managed in the setting of a skilled team consisting of a donor surgeon, a urologist, a transplant surgeon, and an adept anesthesiologist, in an institution with a high number of cases. ${ }^{25}$

\section{Symptomatic treatment}

Treatment of ADPKD is focused on prophylactic and supportive measures, which, in addition to tight blood pressure management, include adequate pain control, antibiotics for urinary tract infections, sufficient fluid intake, and avoidance of caffeine and smoking. ${ }^{2,11,40}$ Urinary tract infections are common during the disease course of ADPKD. Typically, upper and lower urinary tract infections present similarly to patients without ADPKD, and are treated in the same fashion, using cyst-penetrating antibiotics including trimethoprim-sulfamethoxazole and fluoroquinolones. ${ }^{126,127}$ 
Of note, patients with parenchymal and cyst involvement can present with a urinary tract infection and negative urinary cultures, as not all cysts communicate with the urinary space. This presentation should be suspected in patients with a prolonged fever, weight loss, and non-specific gastrointestinal symptoms.

The significant abdominal, back, and flank pain associated with ADPKD is often severe enough to interfere with activities of daily living. ${ }^{128}$ This occurs either as a result of mass effect from the enormous growth of the kidneys, or more acutely due to individual cyst rupture, with pain most frequently occurring in the lower back or abdomen. ${ }^{129}$ Pain management can be difficult in these patients as standard approaches, including use of non-steroidal agents, should be avoided, given their effect on the kidneys. Use of narcotic analgesics should be reserved for acute episodes to minimize the potential for dependence. Despite these strategies, anywhere from $50 \%-70 \%$ of patients with ADPKD have pain that is uncontrolled with oral analgesics. ${ }^{130}$ Accordingly, when conservative measures fail, surgical options are available. These include cyst decortication, which is now performed laparoscopically and has been found in a study of 29 ADPKD patients to result in a greater than 50\% improvement in pain in $73 \%, 52 \%$, and $81 \%$ of patients, at 12, 24, and 36 months, respectively. ${ }^{131}$ Similarly, a different study of 15 ADPKD patients treated with laparoscopic decortication revealed that pain decreased an average of $62 \%$ in $73 \%$ of cases at a mean follow-up of 2.2 years (range 0.5-5). ${ }^{132}$ Further studies are needed to determine the benefits of decortication for longer-term pain relief. Nonetheless, this is not an entirely benign procedure, with reported complications including postoperative bleeding, ileus, worsening hypertension, arrhythmia, pneumonia, and even death. ${ }^{133-135}$ An additional option that holds promise in treating symptoms associated with the mass effect of the kidneys includes renal artery embolization. This procedure involves embolization of the main renal artery, although selective embolization has been attempted. It is typically performed only on dialysis-dependent patients as it eliminates any remaining renal function, essentially decreasing GFR to zero. This is important to consider in those ESRD patients with some residual renal function, as renal artery embolization will eliminate this remaining function and its potential quality of life benefits. Nonetheless, the procedure has been shown in a number of studies to effectively treat hematuria and decrease kidney size, with only minimal side effects that include temporary flank pain, fever, and nausea and vomiting. ${ }^{136,137}$ The data supporting use of this modality over other more invasive approaches is limited, and open or laparoscopic nephrectomy with transplantation remains the treatment of choice in patients with ESRD and intractable pain. ${ }^{17}$ Nonetheless, embolization seems to be an effective option in ADPKD patients and may be most useful in those in which transplantation is not possible. ${ }^{138}$

Other indications for nephrectomy in ADPKD patients with ESRD include cyst rupture, hemorrhage, renal calculi, hypertension, and persistent infection. ${ }^{139}$ When conservative measures fail, explantation may also be utilized to relieve mass effect symptoms, including pain, shortness of breath, and early satiety resulting from renal displacement of adjacent structures and organs, with a 2000 study showing complete elimination of preoperative pain in all 9 patients undergoing laparoscopic nephrectomy. ${ }^{140}$

Cases of nephrolithiasis can generally be treated with conservative measures including hydration, analgesia, and treatment of any associated infections. ${ }^{24}$ Potassium citrate can also be utilized in cases of uric acid nephrolithiasis, hypocitraturic calcium oxalate nephrolithiasis, and distal acidification defects. ${ }^{12}$ When conservative measures fail, alternative approaches to stone therapy may include extracorporeal shockwave lithotripsy and percutaneous nephrostolithotomy. Prophylactic measures should include good water intake.

\section{Novel therapies}

mTOR inhibitors

Characteristic to ADPKD is enhanced renal tubular epithelial cell proliferation, which has been shown in humans and animal models of ADPKD to be related to activation of the mTOR pathway. ${ }^{2,141,142}$ Accordingly, novel therapies for ADPKD include use of inhibitors of the mTOR pathway, with agents that include rapamycin and everolimus, shown in animal models to slow cyst expansion and preserve renal function. ${ }^{141-143}$

Recent evidence for the use of rapamycin in humans comes from a 2009 randomized, single-blind study that followed 8 patients with ADPKD treated with $1 \mathrm{mg}$ /day of rapamycin by mouth daily for 6 months, in addition to the angiotensin receptor blocker, telmisartan. ${ }^{144}$ Another 8 patients with ADPKD received only telmisartan, representing the control group. All the patients involved in the study had creatinines under $2.0 \mathrm{mg} / \mathrm{dL}$, with negative urine cultures, prior to the beginning of the study. Of the patients who were treated with rapamycin, 5/8 had stable renal function at the study's completion, with 2 showing improved renal function and 1 demonstrating a worsening creatinine, resulting in the patient withdrawing from the study. In contrast, of 
the control patients receiving only the ARB, renal function remained stable in 3, became worse in 3, and improved in 2 . Complications in the treatment group included urinary tract infection in 2 patients, and monilial pharyngitis in another 2 , compared to only 2 infections in the control group. Most notably, MRIs obtained at the beginning of the study and again following 6 months of therapy revealed a significant rise in kidney volume in the control group (from $2667 \mathrm{~mL}$ to $3590 \mathrm{~mL}$ at 6 months), compared to the treatment group, who experienced a much smaller volume increase $(2845 \mathrm{~mL}$ to $3221 \mathrm{~mL}$ at 6 months). Accordingly, the authors conclude that rapamycin may prove to be beneficial, in combination with an ARB, in the treatment of ADPKD. Confirmatory studies, with longer follow-up and greater numbers of patients are currently underway, with definitive data expected to be available in $2010 .^{2}$

\section{Vasopressin receptor antagonists}

In addition to mTOR-regulated cell proliferation, cyst formation and growth is thought to be due in part to enhanced fluid secretion from renal tubular epithelial cells. This process of fluid secretion is driven by a number of signaling cascades, including those related to cAMP generation. Accordingly, agents that disrupt this pathway, such as vasopressin receptor antagonists, have been considered to be a potential treatment approach. Vasopressin receptor antagonists act by disrupting the binding of vasopressin to $\mathrm{V} 2$ receptors normally expressed in kidney collecting ducts, the primary location where ARPKD cysts derive, and possibly ADPKD as well. ${ }^{145}$ Normally, upon binding to V2 receptors, vasopressin stimulates adenylyl cyclase to produce cAMP, stimulating cyst formation and growth through promotion of fluid secretion and proliferative activity of cyst epithelial cells. ${ }^{40,146}$ Accordingly, since patients with PKD have been found to have elevated vasopressin levels, by blocking this pathway, it was thought that disease progression may be disrupted and potentially inhibited when treated early in the disease course. ${ }^{147-149}$ This has been shown in a number of studies, first in a 1999 study by Gattone et al which found that OPC-31260, a V2 receptor antagonist, led to amelioration of cystic enlargement and azotemia in a cpk mouse, a model of rapidly progressive cystic disease. ${ }^{145}$ Subsequent studies have produced similar results using OPC-31260 in animal models orthologous to human ADPKD, ARPKD (PCK rat), and adolescent nephronophthisis. ${ }^{146,150}$ Other studies have shown that tolvaptan, a vasopressin receptor antagonist FDA approved for the treatment of clinically-significant hypervolemic and euvolemic hyponatremia, may also be effective in animal models of PKD, with this drug having even stronger V2 binding. ${ }^{151}$ Accordingly, a number of studies analyzing the effects of tolvaptan in humans have been undertaken as part of the Tolvaptan Efficacy and Safety in Management of PKD and Outcomes (TEMPO) program, in order to more definitely define its potential role in ADPKD. Results from the phase 2 component of the study have found tolvaptan to be safe and well-tolerated in ADPKD. ${ }^{145}$ A large, placebo-controlled, double-blind study, representing phase 3 of the program is currently in progress, studying 18 to 50 -year-old patients with ADPKD, preserved renal function, and relatively rapidly progressing disease, as defined by total kidney volumes over $750 \mathrm{~mL}$ (TEMPO 3/4 study; NCT00428948). ${ }^{2,145}$ Results of the study should clarify the efficacy of tolvaptan in slowing disease progression.

\section{Octreotide}

Octreotide has therapeutic potential via inhibition of cAMP production. ${ }^{40}$ Somatostatin was first thought to be a potential treatment option for patients with ADPKD after it was incidentally found that a patient with ADPKD and a pituitary adenoma being treated with somatostatin had stabilization of their renal cyst size. ${ }^{152}$ Somatostatin has since been shown in animal models to lower serum cAMP levels and reduce kidney weights, cyst volumes, and renal fibrosis in PCK rats, although it has not been found to have any effect on renal function. ${ }^{153}$ In humans, octreotide has been shown in a 6 month, randomized, cross-over, placebo-controlled trial to be well-tolerated and to significantly slow renal volume expansion, particularly by retarding the growth of smaller sized cysts. ${ }^{152}$ Again, notably, octreotide was found to have no effect on GFR compared to controls. Long term benefits of the drug remain unknown, with studies underway to further evaluate somatostatin's role in treatment. ${ }^{40}$

\section{Additional agents}

Other investigational agents in ADPKD include roscovitine, triptolide, pioglitazone, and etanercept, the roles of which may become more clear with time. ${ }^{40}$ As more data becomes available about the many investigational drugs being tested in PKD (Table 3), new treatment recommendations may become available that could benefit these patients. In the meantime, patients should be advised to follow current management recommendations.

\section{ARPKD}

Disease-specific therapies for ARPKD are lacking, and treatment is therefore directed towards management of associated 
Table 3 Select novel therapies in PKD

\begin{tabular}{|c|c|c|}
\hline Drug name/class & Mechanism of action & Supporting data \\
\hline mTOR inhibitors & $\begin{array}{l}\text { Inhibition of mTOR signaling } \\
\text { cascade, disrupting renal } \\
\text { epithelial cell proliferation }\end{array}$ & $\begin{array}{l}\text { Randomized, single-blind study } \\
\text { showing significant slowing of renal } \\
\text { size in patients treated with } \\
\text { rapamycin and telmisartan, compared } \\
\text { to telmisartan alone }\end{array}$ \\
\hline $\begin{array}{l}\text { Vasopressin receptor } \\
\text { antagonists }\end{array}$ & $\begin{array}{l}\text { Disruption of binding of } \\
\text { vasopressin to V } 2 \text { receptors, } \\
\text { inhibiting cAMP-associated } \\
\text { signaling cascades }\end{array}$ & $\begin{array}{l}\text { Phase } 2 \text { results show tolvaptan to be } \\
\text { safe and well-tolerated; phase } 3 \\
\text { studies in progress }\end{array}$ \\
\hline Octreotide & Inhibition of cAMP production & $\begin{array}{l}\text { Shown in a randomized, cross-over, } \\
\text { placebo-controlled trial to } \\
\text { significantly slow renal volume } \\
\text { expansion; no effect on GFR }\end{array}$ \\
\hline
\end{tabular}

Abbreviations: mTOR, mammalian target of rapamycin; cAMP, cyclic adenosine monophosphate.

complications, which commonly include respiratory insufficiency, hypertension, growth retardation, electrolyte abnormalities, hepatic manifestations, and acute and chronic renal insufficiency. ${ }^{36}$ Respiratory complications in ARPKD can be severe and may require prolonged mechanical ventilation and neonatal intensive care support. Hypertension in these patients often requires multiple antihypertensive agents and is typically responsive to ACE inhibitors. ${ }^{36}$ Growth retardation related to increased metabolic demands, poor feeding, and early satiety can be addressed with gastrostomy or nasogastric tubes feedings. Electrolyte abnormalities, including hyponatremia, should be treated as needed, and may require changes in water and sodium intake. ${ }^{104}$ Congenital hepatic fibrosis and its associated complications should be followed closely by pediatric gastroenterologists, and may require periodic endoscopy with variceal banding, as well as portosystemic shunting. ESRD is treated with renal replacement therapies, including dialysis and renal transplantation.

\section{Conclusion}

Autosomal dominant polycystic kidney disease is one of the most common inheritable conditions. With an incidence 10 times that of sickle cell disease and 15 times that of cystic fibrosis, effective treatment options for ADPKD are widely sought, but remain an elusive goal. ${ }^{23}$ Recent advances in the understanding of the genetic and molecular pathogenesis of both ADPKD and ARPKD have resulted in new, targeted therapies designed to disrupt cell signaling pathways responsible for the abnormal cell proliferation, dedifferentiation, apoptosis, and fluid secretion characteristic of the disease. ${ }^{40}$ Although definitive cures are still lacking, many of these newer therapeutic agents show promise in preventing or stabilizing cyst growth, providing much needed hope in this currently relentless condition.

\section{Disclosure}

The authors report no conflicts of interest.

\section{References}

1. Chapman AB. Approaches to testing new treatments in autosomal dominant polycystic kidney disease: Insights from the CRISP and HALT-PKD studies. Clin J Am Soc Nephrol. 2008;3:1197-1204.

2. Wuthrich RP, Serra AL, Kistler AD. Autosomal dominant polycystic kidney disease: New treatment options and how to test their efficacy. Kidney Blood Press Res. 2009;32:380-387.

3. Franz KA, Reubi FC. Rate of functional deterioration in polycystic kidney disease. Kidney Int. 1983;23:526-529.

4. Churchill DN, Bear JC, Morgan J, Payne RH, McManamon PJ, Gault MH. Prognosis of adult onset polycystic kidney disease re-evaluated. Kidney Int. 1984;26:190-193.

5. Guay-Woodford LM, Desmond RA. Autosomal recessive polycystic kidney disease: The clinical experience in North America. Pediatrics. 2003;111:1072-1080.

6. Kaimori JY, Germino GG. ARPKD and ADPKD: First cousins or more distant relatives? J Am Soc Nephrol. 2008;19:416-418.

7. Capisonda R, Phan V, Traubuci J, Daneman A, Balfe JW, Guay-Woodford LM. Autosomal recessive polycystic kidney disease: Outcomes from a single-center experience. Pediatr Nephrol. 2003;18: 119-126.

8. Zerres K, Mucher G, Becker J, et al. Prenatal diagnosis of autosomal recessive polycystic kidney disease (ARPKD): Molecular genetics, clinical experience, and fetal morphology. Am J Med Genet. 1998; $76: 137-144$

9. Blyth H, Ockenden BG. Polycystic disease of kidney and liver presenting in childhood. J Med Genet. 1971;8:257-284.

10. Zerres K, Mucher G, Bachner L, et al. Mapping of the gene for autosomal recessive polycystic kidney disease (ARPKD) to chromosome 6p21-cen. Nat Genet. 1994;7:429-432.

11. Bennett WM. Autosomal dominant polycystic kidney disease: 2009 update for internists. Korean J Intern Med. 2009;24:165-168.

12. Torres VE, Harris PC, Pirson Y. Autosomal dominant polycystic kidney disease. Lancet. 2007;369:1287-1301.

13. Chapman AB, Schrier RW. Pathogenesis of hypertension in autosomal dominant polycystic kidney disease. Semin Nephrol. 1991;11: 653-660.

14. Gabow PA, Chapman AB, Johnson AM, et al. Renal structure and hypertension in autosomal dominant polycystic kidney disease. Kidney Int. 1990;38:1177-1180.

15. Chapman AB, Gabow PA. Hypertension in autosomal dominant polycystic kidney disease. Kidney Int Suppl. 1997;61:S71-S73. 
16. Wang R, Moudgil A, Jordan SC. Cystic diseases of the kidney. In: Rimoin DL, Pyeritz RE, Emery AE, Connor JM, editors. Emery and Rimoin's Principles and Practice of Medical Genetics, Vol. 1. 3rd ed. Philadelphia: Elsevier Health Sciences; 1996:1478.

17. Badani KK, Hemal AK, Menon M. Autosomal dominant polycystic kidney disease and pain - a review of the disease from aetiology, evaluation, past surgical treatment options to current practice. J Postgrad Med. 2004;50:222-226.

18. Ryu SJ. Intracranial hemorrhage in patients with polycystic kidney disease. Stroke. 1990;21:291-294.

19. Schievink WI, Torres VE, Wiebers DO, Huston J 3rd. Intracranial arterial dolichoectasia in autosomal dominant polycystic kidney disease. J Am Soc Nephrol. 1997;8:1298-1303.

20. Stiasny B, Schulze BD, Graf S, Weber M. Vessel malformation in a patient with ADPKD: Megadolichobasilar artery, abdominal aortic and iliac aneurysms. Contrib Nephrol. 1995;115:182-184.

21. Larranaga J, Rutecki GW, Whittier FC. Spontaneous vertebral artery dissection as a complication of autosomal dominant polycystic kidney disease. Am J Kidney Dis. 1995;25:70-74.

22. Adubofour K, Sidaway L, Glatter T. Coronary artery aneurysms in association with adult polycystic kidney disease. Am Heart J. 1994; 127:1411-1413.

23. Gabow PA. Autosomal dominant polycystic kidney disease. $N$ Engl $J$ Med. 1993;329:332-342.

24. Chow CL, Ong AC. Autosomal dominant polycystic kidney disease. Clin Med. 2009;9:278-283.

25. Nishiura JL, Neves RF, Eloi SR, Cintra SM, Ajzen SA, Heilberg IP. Evaluation of nephrolithiasis in autosomal dominant polycystic kidney disease patients. Clin J Am Soc Nephrol. 2009;4:838-844. Epub 2009 Apr 1.

26. Denamur E, Delezoide AL, Alberti C, et al. Genotype-phenotype correlations in fetuses and neonates with autosomal recessive polycystic kidney disease. Kidney Int. 2010;77:350-358.

27. Shaikewitz ST, Chapman A. Autosomal recessive polycystic kidney disease: Issues regarding the variability of clinical presentation. $J \mathrm{Am}$ Soc Nephrol. 1993;3:1858-1862.

28. Kaariainen H, Jaaskelainen J, Kivisaari L, Koskimies O, Norio R. Dominant and recessive polycystic kidney disease in children: Classification by intravenous pyelography, ultrasound, and computed tomography. Pediatr Radiol. 1988;18:45-50.

29. Heptinstall RH. Pathology of the Kidney. 4th ed. Boston: Little Brown; 1992.

30. Lilova MI, Petkov DL. Intracranial aneurysms in a child with autosomal recessive polycystic kidney disease. Pediatr Nephrol. 2001;16: $1030-1032$

31. Neumann HP, Krumme B, van Velthoven V, Orszagh M, Zerres K. Multiple intracranial aneurysms in a patient with autosomal recessive polycystic kidney disease. Nephrol Dial Transplant. 1999;14: 936-939.

32. Grantham JJ. Polycystic kidney disease: Hereditary and acquired. $A d v$ Intern Med. 1993;38:409-420.

33. Pei Y, Obaji J, Dupuis A, et al. Unified criteria for ultrasonographic diagnosis of ADPKD. J Am Soc Nephrol. 2009;20:205-212.

34. Rossetti S, Consugar MB, Chapman AB, et al. Comprehensive molecular diagnostics in autosomal dominant polycystic kidney disease. J Am Soc Nephrol. 2007;18:2143-2160.

35. Garcia-Gonzalez MA, Jones JG, Allen SK, et al. Evaluating the clinical utility of a molecular genetic test for polycystic kidney disease. Mol Genet Metab. 2007;92:160-167.

36. Kaplan BS, Meyers K. Polycystic kidney diseases. In: Dell KM, editor. Pediatric Nephrology and Urology: The Requisites in Pediatrics. 1st ed. Philadelphia, PA: Mosby; 2004:214-222.

37. Zerres K, Rudnik-Schoneborn S, Deget F, et al. Autosomal recessive polycystic kidney disease in 115 children: Clinical presentation, course and influence of gender. Arbeitsgemeinschaft fur Padiatrische, Nephrologie. Acta Paediatr. 1996;85:437-445.
38. Garel L. Sonography of renal cystic disease and dysplasia in infants and children. In: Brodehl J, Ehrich JHH, editors. Paediatric Nephrology. Berlin: Springer; 1984.

39. Gunay-Aygun M, Tuchman M, Font-Montgomery E, et al. PKHD1 sequence variations in 78 children and adults with autosomal recessive polycystic kidney disease and congenital hepatic fibrosis. Mol Genet Metab. 2010;99:160-173.

40. Patel V, Chowdhury R, Igarashi P. Advances in the pathogenesis and treatment of polycystic kidney disease. Curr Opin Nephrol Hypertens. 2009;18:99-106.

41. Harris PC, Bae KT, Rossetti S, et al. Cyst number but not the rate of cystic growth is associated with the mutated gene in autosomal dominant polycystic kidney disease. J Am Soc Nephrol. 2006;17: 3013-3019.

42. Torra R, Badenas C, Darnell A, et al. Linkage, clinical features, and prognosis of autosomal dominant polycystic kidney disease types 1 and 2. J Am Soc Nephrol. 1996;7:2142-2151.

43. Rossetti S, Kubly VJ, Consugar MB, et al. Incompletely penetrant PKD1 alleles suggest a role for gene dosage in cyst initiation in polycystic kidney disease. Kidney Int. 2009;75:848-855.

44. Bear JC, Parfrey PS, Morgan JM, Martin CJ, Cramer BC. Autosomal dominant polycystic kidney disease: New information for genetic counselling. Am J Med Genet. 1992;43:548-553.

45. Paterson AD, Wang KR, Lupea D, St George-Hyslop P, Pei Y. Recurrent fetal loss associated with bilineal inheritance of type 1 autosomal dominant polycystic kidney disease. Am J Kidney Dis. 2002;40:16-20.

46. Pei Y, Paterson AD, Wang KR, et al. Bilineal disease and transheterozygotes in autosomal dominant polycystic kidney disease. Am J Hum Genet. 2001;68:355-363.

47. Persu A, Duyme M, Pirson Y, et al. Comparison between siblings and twins supports a role for modifier genes in ADPKD. Kidney Int. 2004; 66:2132-2136.

48. McConnell RS, Rubinsztein DC, Fannin TF, et al. Autosomal dominant polycystic kidney disease unlinked to the PKD1 and PKD2 loci presenting as familial cerebral aneurysm. J Med Genet. 2001; 38:238-240.

49. Turco AE, Clementi M, Rossetti S, Tenconi R, Pignatti PF. An Italian family with autosomal dominant polycystic kidney disease unlinked to either the PKD1 or PKD2 gene. Am J Kidney Dis. 1996;28: 759-761.

50. Bogdanova N, Dworniczak B, Dragova D, et al. Genetic heterogeneity of polycystic kidney disease in Bulgaria. Hum Genet. 1995;95:645-650.

51. de Almeida S, de Almeida E, Peters D, et al. Autosomal dominant polycystic kidney disease: Evidence for the existence of a third locus in a Portuguese family. Hum Genet. 1995;96:83-88.

52. Daoust MC, Reynolds DM, Bichet DG, Somlo S. Evidence for a third genetic locus for autosomal dominant polycystic kidney disease. Genomics. 1995;25:733-736.

53. de Almeida E, Martins Prata M, de Almeida S, Lavinha J. Long-term follow-up of a family with autosomal dominant polycystic kidney disease type 3. Nephrol Dial Transplant. 1999;14:631-634.

54. Zhang MZ, Mai W, Li C, et al. PKHD1 protein encoded by the gene for autosomal recessive polycystic kidney disease associates with basal bodies and primary cilia in renal epithelial cells. Proc Natl Acad Sci U SA. 2004;101:2311-2316.

55. Bergmann C, Senderek J, Windelen E, et al. Clinical consequences of PKHD1 mutations in 164 patients with autosomal-recessive polycystic kidney disease (ARPKD). Kidney Int. 2005;67:829-848.

56. Sharp AM, Messiaen LM, Page G, et al. Comprehensive genomic analysis of PKHD1 mutations in ARPKD cohorts. J Med Genet. 2005;42:336-349.

57. Bergmann C, Senderek J, Kupper F, et al. PKHD1 mutations in autosomal recessive polycystic kidney disease (ARPKD). Hum Mutat. 2004:23:453-463.

58. Bergmann C, Senderek J, Schneider F, et al. PKHD1 mutations in families requesting prenatal diagnosis for autosomal recessive polycystic kidney disease (ARPKD). Hum Mutat. 2004;23:487-495. 
59. Bergmann C, Senderek J, Sedlacek B, et al. Spectrum of mutations in the gene for autosomal recessive polycystic kidney disease (ARPKD/ PKHD1). J Am Soc Nephrol. 2003;14:76-89.

60. Zerres K. Mutation Database Autosomal Recessive Polycystic Kidney Disease (ARPKD/PKHD1). Available at: http://www.humgen.rwth aachen.de/ Accessed Dec 16, 2009.

61. Bergmann C, Kupper F, Dornia C, Schneider F, Senderek J, Zerres K. Algorithm for efficient PKHD1 mutation screening in autosomal recessive polycystic kidney disease (ARPKD). Hum Mutat. 2005;25:225-231.

62. Rossetti S, Harris PC. Genotype-phenotype correlations in autosomal dominant and autosomal recessive polycystic kidney disease. J Am Soc Nephrol. 2007;18:1374-1380.

63. Furu L, Onuchic LF, Gharavi A, et al. Milder presentation of recessive polycystic kidney disease requires presence of amino acid substitution mutations. J Am Soc Nephrol. 2003;14:2004-2014.

64. Yoder BK. Role of primary cilia in the pathogenesis of polycystic kidney disease. J Am Soc Nephrol. 2007;18:1381-1388.

65. Praetorius HA, Spring KR. Removal of the MDCK cell primary cilium abolishes flow sensing. J Membr Biol. 2003;191:69-76.

66. Hildebrandt F, Otto E. Cilia and centrosomes: A unifying pathogenic concept for cystic kidney disease? Nat Rev Genet. 2005;6:928-940.

67. Lin F, Hiesberger T, Cordes K, et al. Kidney-specific inactivation of the KIF3A subunit of kinesin-II inhibits renal ciliogenesis and produces polycystic kidney disease. Proc Natl Acad Sci U S A. 2003;100: 5286-5291.

68. Masyuk AI, Gradilone SA, Banales JM, et al. Cholangiocyte primary cilia are chemosensory organelles that detect biliary nucleotides via P2Y12 purinergic receptors. Am J Physiol Gastrointest Liver Physiol. 2008;295:G725-G734.

69. Fischer E, Pontoglio M. Planar cell polarity and cilia. Semin Cell Dev Biol. 2009;20:998-1005.

70. Karner C, Wharton KA Jr, Carroll TJ. Planar cell polarity and vertebrate organogenesis. Semin Cell Dev Biol. 2006;17:194-203.

71. Patel V, Li L, Cobo-Stark P, et al. Acute kidney injury and aberrant planar cell polarity induce cyst formation in mice lacking renal cilia. Hum Mol Genet. 2008;17:1578-1590.

72. Jonassen JA, San Agustin J, Follit JA, Pazour GJ. Deletion of IFT20 in the mouse kidney causes misorientation of the mitotic spindle and cystic kidney disease. J Cell Biol. 2008;183:377-384.

73. Nishio S, Tian X, Gallagher AR, et al. Loss of oriented cell division does not initiate cyst formation. J Am Soc Nephrol. 2010;21:295-302. Epub 2009 Dec 3.

74. Park JY, Schutzer WE, Lindsley JN, et al. P21 is decreased in polycystic kidney disease and leads to increased epithelial cell cycle progression: Roscovitine augments P21 levels. BMC Nephrol. 2007;8:12.

75. Woo D. Apoptosis and loss of renal tissue in polycystic kidney diseases. N Engl J Med. 1995;333:18-25.

76. Ibraghimov-Beskrovnaya O, Bukanov N. Polycystic kidney diseases: From molecular discoveries to targeted therapeutic strategies. Cell Mol Life Sci. 2008;65:605-619.

77. Masoumi A, Reed-Gitomer B, Kelleher C, Schrier RW. Potential pharmacological interventions in polycystic kidney disease. Drugs. 2007;67:2495-2510.

78. Ecder T, Schrier RW. Cardiovascular abnormalities in autosomal-dominant polycystic kidney disease. Nat Rev Nephrol. 2009;5:221-228.

79. Ibraghimov-Beskrovnaya O, Dackowski WR, Foggensteiner L, et al. Polycystin: In vitro synthesis, in vivo tissue expression, and subcellular localization identifies a large membrane-associated protein. Proc Natl Acad Sci US A. 1997;94:6397-6402.

80. Hanaoka K, Qian F, Boletta A, et al. Co-assembly of polycystin-1 and -2 produces unique cation-permeable currents. Nature. 2000;408: 990-994.

81. Nauli SM, Alenghat FJ, Luo Y, et al. Polycystins 1 and 2 mediate mechanosensation in the primary cilium of kidney cells. Nat Genet. 2003;33:129-137. Epub 2003 Jan 6.
82. Nauli SM, Kawanabe Y, Kaminski JJ, Pearce WJ, Ingber DE, Zhou J. Endothelial cilia are fluid shear sensors that regulate calcium signaling and nitric oxide production through polycystin-1. Circulation. 2008;117:1161-1171. Epub 2008 Feb 19.

83. Nauli SM, Zhou J. Polycystins and mechanosensation in renal and nodal cilia. Bioessays. 2004;26:844-856. Review.

84. Sharif-Naeini R, Folgering JH, Bichet D, et al. Polycystin-1 and -2 dosage regulates pressure sensing. Cell. 2009;139:587-596.

85. Morel N, Vandenberg G, Ahrabi AK, et al. PKD1 haploinsufficiency is associated with altered vascular reactivity and abnormal calcium signaling in the mouse aorta. Pflugers Arch. 2009;457:845-856. Epub 2008 Aug 5.

86. Kaariainen H. Polycystic kidney disease in children: A genetic and epidemiological study of 82 Finnish patients. J Med Genet. 1987;24:474-481.

87. Bergmann C, Zerres K. Early manifestations of polycystic kidney disease. Lancet. 2007;369:2157.

88. Dalgaard OZ. Bilateral polycystic disease of the kidneys; a follow-up of 284 patients and their families. Dan Med Bull. 1957;4:128-133.

89. Chapman AB, Guay-Woodford LM, Grantham JJ, et al. Renal structure in early autosomal-dominant polycystic kidney disease (ADPKD): The consortium for radiologic imaging studies of polycystic kidney disease (CRISP) cohort. Kidney Int. 2003;64:1035-1045.

90. Grantham JJ, Torres VE, Chapman AB, et al. Volume progression in polycystic kidney disease. N Engl J Med. 2006;354:2122-2130.

91. Bae KT, Zhu F, Chapman AB, et al. Magnetic resonance imaging evaluation of hepatic cysts in early autosomal-dominant polycystic kidney disease: The consortium for radiologic imaging studies of polycystic kidney disease cohort. Clin J Am Soc Nephrol. 2006;1:64-69.

92. Janssen MJ, Waanders E, Woudenberg J, Lefeber DJ, Drenth JP. Congenital disorders of glycosylation in hepatology: the example of polycystic liver disease. J Hepatol. 2010;52:432-440. Epub 2009 Dec 24.

93. Magistroni R, He N, Wang K, et al. Genotype-renal function correlation in type 2 autosomal dominant polycystic kidney disease. $\mathrm{J} \mathrm{Am}$ Soc Nephrol. 2003;14:1164-1174.

94. Hateboer N, v Dijk MA, Bogdanova N, et al. Comparison of phenotypes of polycystic kidney disease types 1 and 2. European PKD1-PKD2 study group. Lancet. 1999;353:103-107.

95. Johnson AM, Gabow PA. Identification of patients with autosomal dominant polycystic kidney disease at highest risk for end-stage renal disease. J Am Soc Nephrol. 1997;8:1560-1567.

96. Gabow PA, Johnson AM, Kaehny WD, et al. Factors affecting the progression of renal disease in autosomal-dominant polycystic kidney disease. Kidney Int. 1992;41:1311-1319.

97. Fick GM, Johnson AM, Hammond WS, Gabow PA. Causes of death in autosomal dominant polycystic kidney disease. J Am Soc Nephrol. 1995;5:2048-2056.

98. Perrone RD, Ruthazer R, Terrin NC. Survival after end-stage renal disease in autosomal dominant polycystic kidney disease: Contribution of extrarenal complications to mortality. Am J Kidney Dis. 2001;38: 777-784.

99. Levin A, Singer J, Thompson CR, Ross H, Lewis M. Prevalent left ventricular hypertrophy in the predialysis population: Identifying opportunities for intervention. Am J Kidney Dis. 1996;27:347-354.

100. Chapman AB, Johnson AM, Rainguet S, Hossack K, Gabow P, Schrier RW. Left ventricular hypertrophy in autosomal dominant polycystic kidney disease. J Am Soc Nephrol. 1997;8:1292-1297.

101. Belz MM, Hughes RL, Kaehny WD, et al. Familial clustering of ruptured intracranial aneurysms in autosomal dominant polycystic kidney disease. Am J Kidney Dis. 2001;38:770-776.

102. Cole BR, Conley SB, Stapleton FB. Polycystic kidney disease in the first year of life. J Pediatr. 1987;111:693-699.

103. Gagnadoux MF, Habib R, Levy M, Brunelle F, Broyer M. Cystic renal diseases in children. Adv Nephrol Necker Hosp. 1989;18:33-57.

104. Kaplan BS, Fay J, Shah V, Dillon MJ, Barratt TM. Autosomal recessive polycystic kidney disease. Pediatr Nephrol. 1989;3:43-49. 
105. Gang DL, Herrin JT. Infantile polycystic disease of the liver and kidneys. Clin Nephrol. 1986;25:28-36.

106. Beaunoyer M, Snehal M, Li L, Concepcion W, Salvatierra O Jr, Sarwal M. Optimizing outcomes for neonatal ARPKD. Pediatr Transplant. 2007;11:267-271.

107. Roy S, Dillon MJ, Trompeter RS, Barratt TM. Autosomal recessive polycystic kidney disease: Long-term outcome of neonatal survivors. Pediatr Nephrol. 1997;11:302-306.

108. Jamil B, McMahon LP, Savige JA, Wang YY, Walker RG. A study of long-term morbidity associated with autosomal recessive polycystic kidney disease. Nephrol Dial Transplant. 1999;14:205-209.

109. Mattoo TK, Khatani Y, Ashraf B. Autosomal recessive polycystic kidney disease in 15 Arab children. Pediatr Nephrol. 1994;8:85-87.

110. Ecder T, Edelstein CL, Fick-Brosnahan GM, et al. Diuretics versus angiotensin-converting enzyme inhibitors in autosomal dominant polycystic kidney disease. Am J Nephrol. 2001;21:98-103.

111. Ecder T, Chapman AB, Brosnahan GM, Edelstein CL, Johnson AM, Schrier RW. Effect of antihypertensive therapy on renal function and urinary albumin excretion in hypertensive patients with autosomal dominant polycystic kidney disease. Am J Kidney Dis. 2000;35:427-432.

112. van Dijk MA, Breuning MH, Duiser R, van Es LA, Westendorp RG. No effect of enalapril on progression in autosomal dominant polycystic kidney disease. Nephrol Dial Transplant. 2003;18:2314-2320.

113. Chapman AB, Johnson A, Gabow PA, Schrier RW. The reninangiotensin-aldosterone system and autosomal dominant polycystic kidney disease. N Engl J Med. 1990;323:1091-1096.

114. Nakao N, Yoshimura A, Morita H, Takada M, Kayano T, Ideura T. Combination treatment of angiotensin-II receptor blocker and angiotensin-converting-enzyme inhibitor in non-diabetic renal disease (COOPERATE): a randomised controlled trial. Lancet. 2003;361: $117-124$

115. Strippoli GF, Craig M, Deeks JJ, Schena FP, Craig JC. Effects of angiotensin converting enzyme inhibitors and angiotensin II receptor antagonists on mortality and renal outcomes in diabetic nephropathy: systematic review. BMJ. 2004;329:828. Epub 2004 Sep 30. Review.

116. McPherson EA, Luo Z, Brown RA, et al. Chymase-like angiotensin II-generating activity in end-stage human autosomal dominant polycystic kidney disease. J Am Soc Nephrol. 2004;15:493-500.

117. Horky K. Direct renin inhibitor aliskiren in the treatment of cardiovascular and renal diseases. Vnitr Lek. 2010;56:120-126.

118. Grantham JJ. Clinical practice. Autosomal dominant polycystic kidney disease. $N$ Engl J Med. 2008;359:1477-1485.

119. Del Peso G, Bajo MA, Costero O, et al. Risk factors for abdominal wall complications in peritoneal dialysis patients. Perit Dial Int. 2003;23:249-254.

120. Fletcher S, Turney JH, Brownjohn AM. Increased incidence of hydrothorax complicating peritoneal dialysis in patients with adult polycystic kidney disease. Nephrol Dial Transplant. 1994;9:832-833.

121. Graham AN, Neale TJ, Hatfield PJ, et al. Endstage renal failure due to polycystic kidney disease managed by continuous ambulatory peritoneal dialysis. $N$ Z Med J. 1986;99:491-493.

122. Kumar S, Fan SL, Raftery MJ, Yaqoob MM. Long term outcome of patients with autosomal dominant polycystic kidney diseases receiving peritoneal dialysis. Kidney Int. 2008;74:946-951.

123. Pirson Y, Christophe JL, Goffin E. Outcome of renal replacement therapy in autosomal dominant polycystic kidney disease. Nephrol Dial Transplant. 1996;11 Suppl 6:24-28.

124. Goncalves S, Guerra J, Santana A, Abreu F, Mil-Homens C, Gomes da Costa A. Autosomal-dominant polycystic kidney disease and kidney transplantation: Experience of a single center. Transplant Proc. 2009;41:887-890.

125. Kramer A, Sausville J, Haririan A, Bartlett S, Cooper M, Phelan M. Simultaneous bilateral native nephrectomy and living donor renal transplantation are successful for polycystic kidney disease: the University of Maryland experience. J Urol. 2009;181:724-728. Epub 2008 Dec 16.
126. Elzinga LW, Golper TA, Rashad AL, Carr ME, Bennett WM. Trimethoprim-sulfamethoxazole in cyst fluid from autosomal dominant polycystic kidneys. Kidney Int. 1987;32:884-888.

127. Elzinga LW, Golper TA, Rashad AL, Carr ME, Bennett WM. Ciprofloxacin activity in cyst fluid from polycystic kidneys. Antimicrob Agents Chemother. 1988;32:844-847.

128. Heiwe S, Bjuke M. "An evil heritage": Interview study of pain and autosomal dominant polycystic kidney disease. Pain Manag Nurs. 2009;10:134-141.

129. Bajwa ZH, Sial KA, Malik AB, Steinman TI. Pain patterns in patients with polycystic kidney disease. Kidney Int. 2004;66:1561-1569.

130. Grantham JJ. Renal pain in polycystic kidney disease: When the hurt won't stop. J Am Soc Nephrol. 1992;2:1161-1162.

131. Lee DI, Andreoni CR, Rehman J, et al. Laparoscopic cyst decortication in autosomal dominant polycystic kidney disease: Impact on pain, hypertension, and renal function. $J$ Endourol. 2003;17:345-354.

132. Dunn MD, Portis AJ, Naughton C, Shalhav A, McDougall EM, Clayman RV. Laparoscopic cyst marsupialization in patients with autosomal dominant polycystic kidney disease. J Urol. 2001;165: 1888-1892.

133. Lee DI, Andreoni CR, Rehman J, et al. Laparoscopic cyst decortication in autosomal dominant polycystic kidney disease: Impact on pain, hypertension, and renal function. $J$ Endourol. 2003;17:345-354.

134. McNally ML, Erturk E, Oleyourryk G, Schoeniger L. Laparoscopic cyst decortication using the harmonic scalpel for symptomatic autosomal dominant polycystic kidney disease. J Endourol. 2001;15:597-599.

135. Fleming TW, Barry JM. Bilateral open transperitoneal cyst reduction surgery for autosomal dominant polycystic kidney disease. $J$ Urol. 1998;159:44-47.

136. Ubara Y. New therapeutic option for autosomal dominant polycystic kidney disease patients with enlarged kidney and liver. Ther Apher Dial. 2006;10:333-341.

137. Somani BK, Nabi G, Thorpe P, Hussey J, McClinton S. Therapeutic transarterial embolisation in the management of benign and malignant renal conditions. Surgeon. 2006;4:348-352.

138. Bremmer MS, Jacobs SC. Renal artery embolization for the symptomatic treatment of adult polycystic kidney disease. Nat Clin Pract Nephrol. 2008;4:236-237.

139. Tiong H, Shim T, Lee Y, Tan JK. Bilateral laparoscopic nephrectomy for autosomal dominant polycystic kidney disease. Internet $J$ Urol. 2009;6:1.

140. Dunn MD, Portis AJ, Elbahnasy AM, et al. Laparoscopic nephrectomy in patients with end-stage renal disease and autosomal dominant polycystic kidney disease. Am J Kidney Dis. 2000;35:720-725.

141. Tao Y, Kim J, Schrier RW, Edelstein CL. Rapamycin markedly slows disease progression in a rat model of polycystic kidney disease. $J \mathrm{Am}$ Soc Nephrol. 2005;16:46-51.

142. Wahl PR, Serra AL, Le Hir M, Molle KD, Hall MN, Wuthrich RP. Inhibition of mTOR with sirolimus slows disease progression in han:SPRD rats with autosomal dominant polycystic kidney disease (ADPKD). Nephrol Dial Transplant. 2006;21:598-604.

143. Wu M, Wahl PR, Le Hir M, Wackerle-Men Y, Wuthrich RP, Serra AL. Everolimus retards cyst growth and preserves kidney function in a rodent model for polycystic kidney disease. Kidney Blood Press Res. 2007;30:253-259.

144. Soliman AR, Ismail E, Zamil S, Lotfy A. Sirolimus therapy for patients with adult polycystic kidney disease: A pilot study. Transplant Proc. 2009;41:3639-3641.

145. Torres VE. Role of vasopressin antagonists. Clin J Am Soc Nephrol. 2008;3:1212-1218.

146. Gattone VH 2nd, Wang X, Harris PC, Torres VE. Inhibition of renal cystic disease development and progression by a vasopressin V2 receptor antagonist. Nat Med. 2003;9:1323-1326.

147. Seeman T, Dusek J, Vondrak K, et al. Renal concentrating capacity is linked to blood pressure in children with autosomal dominant polycystic kidney disease. Physiol Res. 2004;53:629-634. 
148. Michalski A, Grzeszczak W. The effect of hypervolemia on electrolyte level and level of volume regulating hormones in patients with autosomal dominant polycystic kidney disease. Pol Arch Med Wewn. 1996;96:329-343.

149. Danielsen H, Pedersen EB, Nielsen AH, Herlevsen P, Kornerup HJ, Posborg V. Expansion of extracellular volume in early polycystic kidney disease. Acta Med Scand. 1986;219:399-405.

150. Torres VE, Wang X, Qian Q, Somlo S, Harris PC, Gattone VH 2nd. Effective treatment of an orthologous model of autosomal dominant polycystic kidney disease. Nat Med. 2004;10:363-364.

151. Wang X, Gattone V 2nd, Harris PC, Torres VE. Effectiveness of vasopressin V2 receptor antagonists OPC-31260 and OPC-41061 on polycystic kidney disease development in the PCK rat. J Am Soc Nephrol. 2005;16:846-851.
152. Ruggenenti P, Remuzzi A, Ondei P, et al. Safety and efficacy of long-acting somatostatin treatment in autosomal-dominant polycystic kidney disease. Kidney Int. 2005;68:206-216.

153. Masyuk TV, Masyuk AI, Torres VE, Harris PC, Larusso NF. Octreotide inhibits hepatic cystogenesis in a rodent model of polycystic liver disease by reducing cholangiocyte adenosine 3',5'-cyclic monophosphate. Gastroenterology. 2007;132:1104-1116.

\section{Publish your work in this journal}

The International Journal of Nephrology and Renovascular Disease is an international, peer-reviewed open-access journal focusing on the pathophysiology of the kidney and vascular supply. Epidemiology, screening, diagnosis, and treatment interventions are covered as well as basic science, biochemical and immunological studies. The journal welcomes original research, clinical studies, reviews \& evaluations, expert opinion and commentary, case reports and extended reports. The manuscript management system is completely online and includes a very quick and fair peerreview system, which is all easy to use. Visit http://www.dovepress.com/ testimonials.php to read real quotes from published authors.

Submit your manuscript here: http://www.dovepress.com/international-journal-of-nephrology-and-renovascular-disease-journal 